\title{
Learning from Industry by Using an Inquiry Based Learning Approach
}

\author{
Xiaosong Li \\ Department of Computing \& Information Technology \\ Unitec Institute of Technology \\ Auckland, New Zealand \\ xli@unitec.ac.nz
}

\begin{abstract}
Inquiry based and constructivist activities can motivate students to take charge of their own learning, understand multiple perspectives and develop high level reasoning skills.

This paper describes a case study of six year teaching practice in one of our Master courses. The course requires the students to acquire critically analysis, evaluation and research skills. The course also requires the students to acquire the techniques and technologies related to many aspects of an enterprise website. There are only 32 hours for class meetings so the students have to work by themselves in most of the time. The best way to achieve the course requirements is to use the constructivist activities, let the students individually or collaboratively to work with the relevant partners and build the required knowledge and skills gradually. An assignment was developed which requires the students to investigate different aspects of an enterprise website. To complete this assignment, the students need to use an inquiry based learning approach.
\end{abstract}

The practice is evaluated by using a set of survey data, a set of data observed from the marking reports and the industry feedbacks. The practice is effective, while the practice is improving; the students' abilities of planning, investigating, analyzing, communicating and reflecting are improving as well. The students' contributions are valuable to the industry. The paper also includes a discussion which links the teaching practice with the relevant theories.

Keywords-teaching and learning; inquiry based learning, industry inquiry; website.

\section{INTRODUCTION}

Inquiry based and constructivist activities can motivate students to take charge of their own learning, understand multiple perspectives and develop high level reasoning skills [1]. Bruner's educational theory argues that learning is an active process and knowledge transmission depends on the individuals' participations and reconstructions [2]. We need to work both independently and in collaboration to create engaging learning communities [3]. Much education literature emphasizes the shift away from teacher-centered education to student-centered learning. Interactions, communications or collaboration with more capable peers during problem solving will enhance the learners understanding [3, 4]. When students manipulate artifacts themselves and think freely about problems, they become more actively involved and generally more systematic and scientific in their discovery of laws.

This paper describes a case study of six year teaching practice in one of our Master courses. In a subset of the requirements, the course requires the students be able to

- identify the most common system architecture;

- critically evaluate and determine technologies/tools for developing and maintaining enterprise websites;

- research design issues related to content, appearance, media and architecture;

- analyze the usability \& accessibility for an enterprise website;

- investigate server-side administrative issues;

- evaluate client-side considerations;

- analyze security problems;

- explore management issues relating to security, encryption, verification, site auditing, certification, privacy and copyright.

In summary, the course requires the students to acquire critically analysis, evaluation and research skills. The course also requires the students to acquire the techniques and technologies related to many aspects of an enterprise website. There are only 32 hours for class meetings so the students have to work by themselves in most of the time. The best way to achieve the course requirements is to use the constructivist activities, let the students individually or collaboratively to work with the relevant partners and build the required knowledge and skills gradually. In the inquiry based learning, students are typically presented with a task to do and have to discover for themselves, with teacher facilitation as appropriate, what knowledge gaps they may have and the skills they may need to develop [5]. Inquiry skills improve student ability to acquire knowledge [6] and these skills are particularly important for Master students, so an inquiry based approach should be adopted.

Based on the above understanding, an assignment was developed which requires the students to investigate different aspects of an enterprise website. To complete this assignment, the students need to use an inquiry based learning approach. In 
inquiry based learning, students can also gather information by conducting interviews with local experts, family and community members [1]. The inquiry happens in two ways: using various web based online testing tools and communicating with the administration team of an enterprise website. Students are responsible for arranging their own communication, although suggestions and help may be gained from the lecturers. The students then will report their findings and critique their findings. Creating and demonstrating new knowledge require students gather data but go beyond simply reporting their findings [1]. Students are encouraged to reflect and think independently and critically. This study covers the teaching practice in the time period from the second semester of 2007 to the second semester of 2012. Each semester, we have one class in this course. The student numbers are various from 10 to 27 among the semesters.

The data were collected by observation, informal survey and informal conversations. The data were analyzed to find students' learning in planning, investigating, analyzing, communicating and reflecting. Only one of the classes was surveyed and the questions were around the students' attitudes, practices, the tools used and their industry partners' reaction.

This paper discusses the possible improvements and links the practice with the relevant theories. It also discusses the strategies to overcome the challenges experienced.

In the following sections, the teaching practice is described first, that is followed by the presentation of the data and analysis, then the teaching practice and the relevant theories are discussed, a summary is in the last section.

\section{The TeAChING PRACTICE}

\section{A. The Assignment}

It is an individual assignment and the students are required to work on an existing enterprise website of their own choice with the condition that each student must work on a different website from the rest of the class. The students are required to research aspects of design, architecture, development, administration, management of the website, and then critique. The assignment mainly consists of five components: Technical Report, Architecture Report, Industry Policy Report, Critique and General Presentation. In the first component, the students are asked to investigate technique information such as usability, accessibility, popularity; in the second component they are asked to investigate architecture information such as visual design and content organization. Self-testing and online testing tools are the important instruments for the first two components. In the third component, the students are asked to investigate the management policies of the website such as system maintenance policy, security policy as well as privacy and copyright policy, industry inquiry is the main instrument for this component. In the fourth component, the students are asked to critique on the information gathered from the first three components. The most productive and worthwhile inquiry-based activities require students to gather data but go beyond simply reporting their findings [1].

The tools used include HTML validation tool, CSS validation tool, accessibility testing tool, popularity testing tool (e.g. NetCraft, Alexa), SEO analysis tool (e.g. The Reaction Engine) and technology look up tool (e.g. BuiltWith)

The assignment experienced two main structure changes in the time period covered in this study. Initially, the critique was only required on the information presented in the technique report. It was suggested that the assignment was too easy at Master level. In response to that, since the first semester of 2010, the critique has been required on all the three components: technique, architecture and industry policy. Lately, it was raised that the assignment work load is too heavy, as the students have to submit three reports for this assignment. To address this issue, the three were merged into one report and the critique was integrated with each of the first three components in the second semester of 2012. In the second semester of 2011, the following guideline for the whole process was introduced:

- Gather Information

$\circ$ Source Code and Page Extensions
$\circ$ Online Tools
$\circ$ Client Side Tools
$\circ$ Self-testing and Browsing
$\circ$ Industry Inquiry

- Report Information
- Organise
○ Present
- Analyse
○ Interpret

- Critique by Applying Relevant Guidelines/Principles
- Brief/Refer Information Gathered
○ Link to Relevant Guidelines/Principles
- Books
- Research Literature
- Common Practices
- Online Technique Reports

The case studies of deconstructing website from Smashing Magazine were also introduced and discussed in the second semester of 2011.

\section{B. The Industry Inquieries}

The students are responsible to arrange the communications with their industry partners. Initially, the students send a request to express their interests to study their website as part of the assignment and ask for their support. If the response is positive, the collaboration starts. The students then send a set of questions. The industry partners may not be able to answer all the questions and they may refer the students to their colleagues or their business partners for further inquiry. The students then start to write their reports; they are usually welcome to go back to their industry partners if needed. 


\section{The Classroom Activities}

A number of group classroom activities were designed to equip the students with the required knowledge and skills for the assignment, including news portal evaluation, server monitoring evaluation, web hosting evaluation and search engine optimization activity. The students work in group first and then report their findings to the whole class, there may be inter-group discussions at this stage.

\section{The Challenges}

From the practice of 2012, some of the challenges stood out, which are mainly related to the practical constraints of the learning context, such as it's hard to find an industry partner who is willing to support the assignment, the website management was reluctant to reveal some of the technique and management information due to confidentiality and etc. We encouraged the students to negotiate with their industry partners and get as much information as possible. We also encouraged the students try more options including those oversea websites.

\section{THE DATA ANALYSIS}

\section{A. The Survey Data}

The students from 2010 Semester 1 were surveyed, among 20 students, 16 answered the questions. The survey started with a few general background information questions regarding their experiences related to website, it then focused on the industry inquiry. All the questions related to the industry inquiry and their answers are listed in Table I. All the questions are multiple choice questions except $\mathrm{Qj}$. The participants may select multiple answers for Qg and Qi.

- Qa How easy to gather the data required for your industry report from the administration team?

- Qb How important your industry report to the website administration team?

- Qc Does the administration team appreciate your industry report?

- Qd Does the website administration team appreciate your critique on their management policies?

- Qe Will you provide your industry report including the critique part to the administration team?

- Qf How many staff have you communicated with from the administration team to gather the data?

- Qg In which way did you communicate with the administration team?

- Qh How much have you learned about website management policy from this process?

- Qi How would you like to learn website management policy?

- Qj If you have any other comments on this topic, please write here.
TABLE I. COLLABORATION LEARNING

\begin{tabular}{|c|c|c|c|c|}
\hline Questions & \multicolumn{4}{|c|}{ Answers } \\
\hline \multirow[t]{2}{*}{ Qa } & Easy & $\mathrm{OK}$ & Hard & Other \\
\hline & 2 & 10 & 3 & 1 \\
\hline \multirow[t]{2}{*}{$\mathrm{Qb}$} & $\begin{array}{l}\text { Very } \\
\text { important }\end{array}$ & Important & $\begin{array}{l}\text { Don't } \\
\text { know }\end{array}$ & $\begin{array}{l}\text { Not } \\
\text { important }\end{array}$ \\
\hline & 7 & 7 & 2 & 0 \\
\hline \multirow[t]{2}{*}{ Qc } & Yes & No & \multicolumn{2}{|c|}{ Don't know } \\
\hline & 10 & 1 & \multicolumn{2}{|l|}{5} \\
\hline \multirow[t]{2}{*}{ Qd } & Yes & No & \multicolumn{2}{|c|}{ Don't know } \\
\hline & 9 & 1 & \multicolumn{2}{|l|}{6} \\
\hline \multirow[t]{2}{*}{ Qe } & Yes & No & \multicolumn{2}{|c|}{ Don't know } \\
\hline & 12 & 1 & \multicolumn{2}{|l|}{3} \\
\hline \multirow[t]{2}{*}{ Qf } & 1 & 2 & 3 & $>3$ \\
\hline & 5 & 7 & 2 & 2 \\
\hline \multirow[t]{2}{*}{ Qg } & Email & Phone & $\begin{array}{l}\text { In } \\
\text { person }\end{array}$ & Other \\
\hline & 13 & 6 & 7 & 0 \\
\hline \multirow[t]{2}{*}{ Qh } & Nothing & Little & Average & Plenty \\
\hline & 0 & 1 & 2 & 13 \\
\hline \multirow[t]{2}{*}{ Qi } & Industry & Literature & Lectures & Other \\
\hline & 12 & 11 & 10 & 1 \\
\hline Qj & \multicolumn{4}{|c|}{ In general, they needed more guidance. } \\
\hline
\end{tabular}

The responses to question Qb, Qf, Qg, Qh and Qi are also depicted by a pie graph and bar graphs. Fig. 1 shows the responses to Qf and Fig. 2 shows the responses to Qg. According to Fig. 1, 69\% respondents communicated with more than one staff from their industry partner. According to Fig. 2, 81\% respondents used email for the communication; $38 \%$ used phone and $44 \%$ communicated in person. A student might use multiple ways for the communication. No other methods were specified in this survey, however, according to the informal feedbacks from the students, online chat is also an important method used by the students to communicate with their industry partners. Although the assignment is an individual assignment, collaboration is happening as well. Electronic tools, particularly email, play an import role in this collaboration.

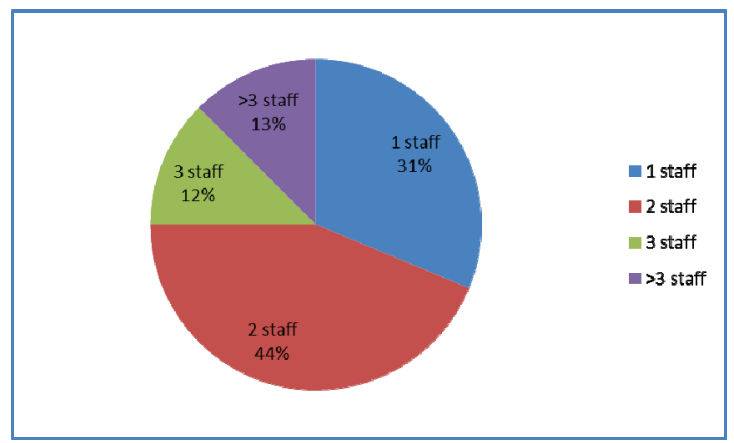

Fig. 1. The number of staff communicated by the students. 


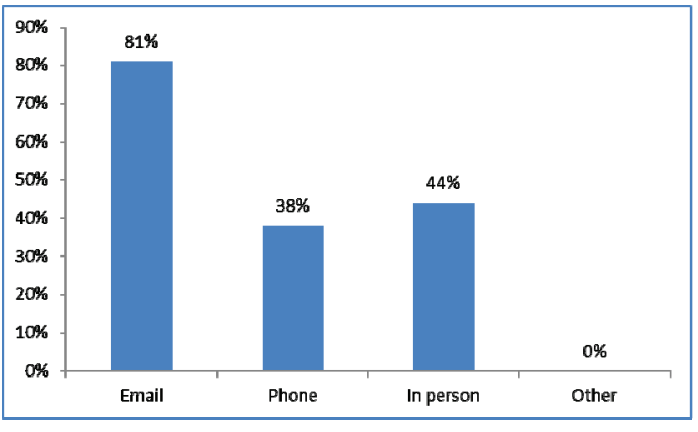

Fig. 2. The methods used to communicate with the industry partners.

The responses to Qb can be found in Fig. 3, which show that $88 \%$ respondents believed their reports important or very important to their industry partners. The responses to Qe in Table I show that more than $75 \%$ respondents would provide their reports to their industry partners. These suggest that the students are not only learning from the industry, their contributions are valuable to the industry as well.

Fig. 4 shows the responses to Qh which solicits students' opinions on their learning from the industry inquiry process. The answer is positive, $81 \%$ respondents believed that they have learned plenty from this process. All the respondents believed that they had learned something from this process. Fig. 5 shows the responses to Qi, which asks the students to select different learning approaches for website management policy. According to Fig. 5, the respondents valued the three given approaches closely, where the industry inquiry was the most favorable $(75 \%)$ and the lectures was the least favorable $(63 \%)$. These suggest that the students believed that inquiry based approach is more suitable for them to learn website management policy although the other supplementary approaches are still needed. One student specified that they also can learn it from previous experience.

In addition to the answers to the multiple choice questions, some students made extra comments, such as "Very good paper, has relevance to industry. Even with my experience, I learnt quite a lot of things regarding importance of policy", "Very enlightening, great impact on website owners and helpful", "This assignment promotes learning", to express their satisfactory. One student made comment of "subject literature should be discussed more in the class" which is interpreted as the students need more guidelines.

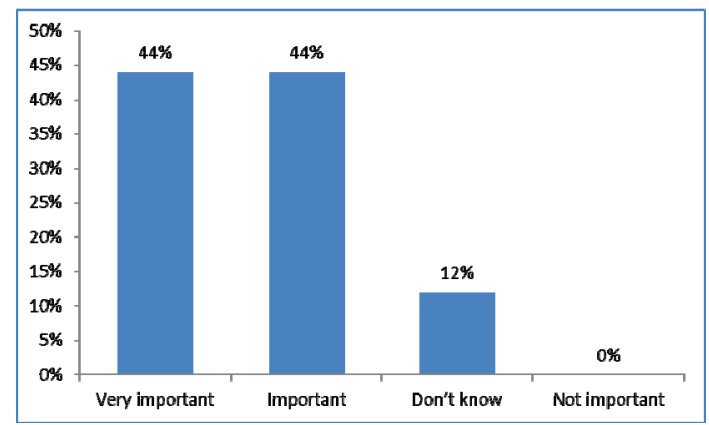

Fig. 3. The students' views on the importance of their reports to their industry partners.

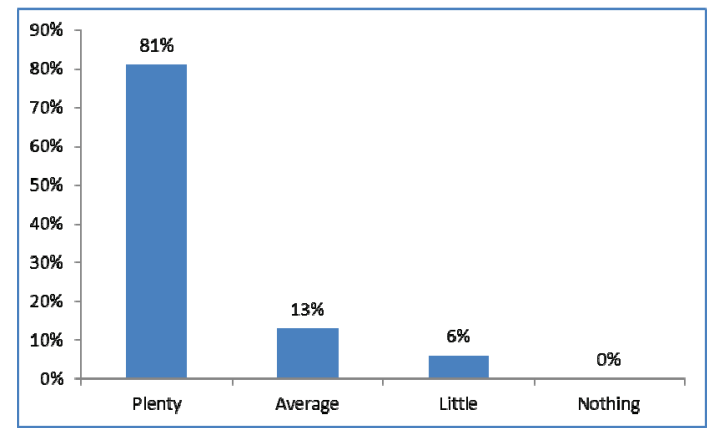

Fig. 4. How much the students have learned.

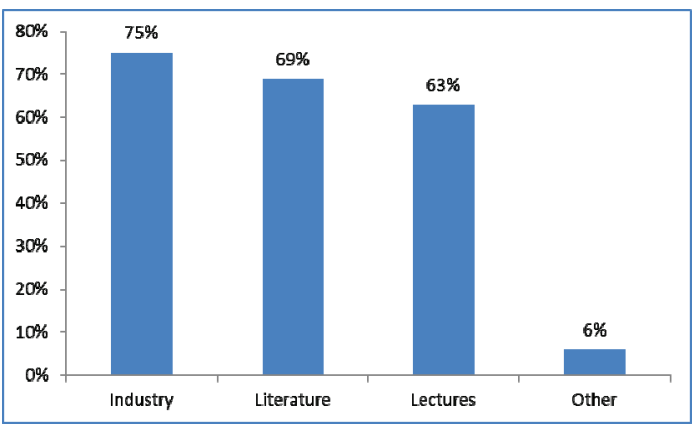

Fig. 5. The learning approaches selected by the students.

\section{B. The Marking Report Data}

After changes and improvements, the assignment was getting mature since 2010. The structure of the assignment was stable from 2010 Semester 1 to 2012 Semester 1. The marking reports in this time period was analyzed to evaluate the student learning from this inquiry based process. Only the marks for management policy report and critique report were analyzed as they are the most relevant part for planning, investigating, analyzing, communicating and reflecting. The students need to plan a set of questions before the industry inquiry and then investigate the website management policies by communicating with their industry partners. The students also need to analyze and reflect on the information gathered in their critique reports. Table II shows the data observed from the marking reports.

From Table II we can see that the marks of the critique reports were relatively low in 2010s1, which were improved in 2010s2 and were further improved later. The standard deviation were larger initially and getting smaller. On the other hand, the marks of the management policy reports had been consistently good in these five semesters. In 2011s2, the marks were further improved.

There is a need to review the improvements introduced in this time period. In 2010s2, the instructions for the critique report had been improved. It was

You should give reasons for your opinions and back them up with specific examples. 
TABLE II. DATA FROM MARKING REPORTS

\begin{tabular}{|l|l|l|l|l|}
\hline Semester & $\begin{array}{c}\text { Policy Mean } \\
(\mathbf{3 0})\end{array}$ & $\begin{array}{c}\text { Critique Mean } \\
(\mathbf{3 0})\end{array}$ & $\begin{array}{c}\text { Policy } \\
\text { STDEV }\end{array}$ & $\begin{array}{c}\text { Critique } \\
\text { STDEV }\end{array}$ \\
\hline $2010 \mathrm{~s} 1$ & $22.58(75.25 \%)$ & $18.55(61.83 \%)$ & 2.60 & 3.41 \\
\hline $2010 \mathrm{~s} 2$ & $22.56(75.21 \%)$ & $21.25(70.83 \%)$ & 2.76 & 3.55 \\
\hline $2011 \mathrm{~s} 1$ & $22.06(73.54 \%)$ & $20.31(67.71 \%)$ & 2.80 & 2.96 \\
\hline $2011 \mathrm{~s} 2$ & $24.04(80.12 \%)$ & $22.26(74.20 \%)$ & 2.42 & 3.05 \\
\hline $2012 \mathrm{~s} 1$ & $23.47(78.25 \%)$ & $22.47(74.91 \%)$ & 2.22 & 2.06 \\
\hline
\end{tabular}

In the survey conducted in $2010 \mathrm{~s} 1$, a student expressed that they need more guidelines on these reports. In response to that, more research articles were introduced and discussed in the classes in 2010s2 and the instructions for the critique report became:

You should give reasons for your opinions and back them up with specific examples. You should summarize the facts you are critiquing and then apply the principles given in the lectures or literature with proper referencing.

Table II suggests that the above changes had a positive impact on the marks of critique report and had no impact on the management policy reports. In 2011 Semester 2, a guideline for this assignment was introduced. Table II suggests that the guideline had a positive impact on the marks for both of critique reports and management policy reports. The standard deviations for the marks of management policy reports were quite consistent and they were further improved since 2011s2. However, the standard deviations for the marks of critique reports were larger at the beginning and they became smaller since $2011 \mathrm{~s} 1$. These suggest that while the teaching practice is improving, the students' abilities of planning, investigating, analyzing, communicating and reflecting are improving as well.

\section{The Industry Reaction}

The industry reaction was gathered by student feedbacks and the emails voluntarily sent by the industry partners.

Initially when the students express their interests to study a particular website, the administration teams may not response at all due to their busy work or confidentiality. Then the students have to try next option. According to the responses to Qa in Table I, more than 75\% respondents didn't think it's hard to find an industry partner. As a matter of fact, some of the website administration teams are very happy to support the students, "It's my pleasure to help you out regarding on your research. Also it was glad that you have selected my project for you assignment".

After the students start to ask questions, some of the industry partners start to hesitate due to certain sensitive questions. We encourage the students to negotiate with their industry partners and get as much information as possible. If it's still difficult, we encourage the students try more options including those websites hosted overseas. Online communication tools can help for remote collaboration [7]. According to Fig. 2, most of the students have used phone and email in their communications, more tools used in [7], such as online chat, online forum and peer-to-peer messaging can be used by the students to communicate with their oversea industry partners effectively.

If the inquiry goes well, finally, most of the students will present their reports to their industry partners. According to the responses to $\mathrm{Qd}$ in Table I, more than 56\% respondents believed that their industry partners appreciated their reports and their critiques. This is confirmed by the emails from three industry partners, "Your report looks great, awesome work. Your paper is quite timely as we are going through a redevelopment project of the website because of a lot of issues you have outlined", "Thank you for your report document - it is an interesting read!", "I am quite impressed by the work had been done. The reports contain high amount of useful information and analysis that are needed in our system. We could update some information about what knowledge of current student learning. At same time, we could have opportunity to refresh our knowledge of IT field".

\section{DISCUSSION}

According to [5], the characteristics of inquiry based learning include:

1. The task is based on an open problem - open in the sense that there are numerous approaches to solution;

2. Initially, the student(s) are presented with the problem, and must discover for themselves the nature of the problem, and in particular to identify what knowledge and skills they will need to investigate and develop in order to solve the problem;

3. Where students are required to demonstrate selfanalysis and critical thinking in order to choose between a number of possible solutions and approaches;

4. Where the teacher or lecturer acts as a facilitator in the process - but avoids simply providing solutions or being prescriptive in approaches.

Interpreting the above in the context of our teaching practice should help to validate the practice:

1. The students are asked to investigate the technique and management aspects of an enterprise website, which is an open problem;

2. Initially, the student(s) are presented with the assignment, the students need to identify their industry partner, the students need to decide what tools they need to use and what questions they need to ask;

3. Where students are required to demonstrate selfanalysis and critical thinking in their reports;

4. The lecturer acts as a facilitator in the lectures and class activities, and provides outside classroom support.

Based on above, the teaching practice does have the characteristics of inquiry based learning. 
"A WebQuest is an inquiry-oriented activity in which some or all of the information that learners interact with comes from resources on the Internet" $[1,6]$. WebQuests are designed to use learners' time well, to focus on using information rather than looking for it, and to support learners' thinking at the levels of analysis, synthesis and evaluation [1]. Although our teaching practice was not designed in a WebQuest format, these purposes are consistent with our initial considerations. It should be helpful to check the teaching practice with the WebQuests to formalize this process and to identify the merits and demerits of the teaching practice for future improvements.

The outline of a WebQuest given by [1] includes:

- Introduction

○ To prepare and hook the students

- Task

○ What the student is going to do

- A description of the culminating performance or product

- Process

- How the learners will accomplish the task

- Clear steps to accomplish the tasks

- Tools and resources they will need to gather and organize information

- Evaluation

- Criteria needed to meet performance and content standards

- Conclusion

- To bring closure

○ To encourage reflection

- Teacher's page

- Information to help other teachers implement the WebQuest:

○ Targeted learners

- Standards

○ Suggestions for teaching the unit

○ Sample student work (sometimes)

The WebQuest used in [6] contains the following stages:

1. Introduction - sets the stage; provide background information about the scenario.

2. Pooling knowledge - an opportunity for students to discuss the issue, drawing on, and combining, prior knowledge, and to stimulate critical reflection.

3. The team-allocation of specific roles for group members.

4. The task-explanation of the expected outcome from the group.
5. Where to look - students working in role, individually or in pairs, research links to appropriate web resources.

6. Getting together-time to share and synthesize findings within groups, and put together a presentation.

7. Share and Review - group presentations and questions.

Both of the WebQuests from [1] and [6] include Introduction and Task parts. [1] contains Process part and [6] contains Where to look part. [1] contains Evaluation and Conclusion; [6] contains Getting together and Share and Review. [1] contains Teacher's page; [6] contains Pooling knowledge. While these two versions share many common components, [1] emphases the process and allows more flexibility, for example, the inquiries are not limited to the Internet; the students can also get information from their community experts; [6] focuses on group activity. WebQuests are usually collaborative ventures, requiring students to work in groups, often with particular assigned roles [6]. Our assignment is an individual assignment which is supported by the class activities and accompanied by the collaboration with the industry partners. A mixed version should reflect this teaching practice better. The following is a WebQuest with the context of our teaching practice:

1. Introduction-define the assignment requirements discuss them with the students in the classes.

2. Pooling knowledge — relevant class activities to equip the students with required knowledge and skills.

3. The tasks-explain what are expected from the students' reports.

4. Industry Partner - the students to find a website they will study and the administration team they will work with.

5. Process - a guideline for the whole process is given; a set of tools are provided for the students to decide which tool to use and what information to collect. The students will analyze and organize the information gathered. The students will critique on the information presented by applying the principles found from various sources (lectures, literature and etc.)

6. Evaluation - a marking guide is provided in the assignment and is discussed in the classes.

The above list validated our teaching practice from WebQuest perspective. However, a Review and Reflection step seems missed. Adding this step by asking the students to do a presentation on their report should improve the teaching practice.

Research showed that university-industry links often rely on informal and formal social links [8]. Matching between universities and firms rarely occurs as the result of a search involving complete information on the whole range of options available to a firm [8]. This explains the challenge some students are having: it's hard to find an industry partner. A possible solution is to encourage the students to use their social network. Another possible solution is for the lecturer to maintain a potential industry partner pool. Initially, the pool 
should contain those industry partners collaborated with the past students, the pool should be regularly updated by removing those who are not interested to participate anymore and adding new industry partners who are interested.

On an individual level, the question is how the academic researchers and industry staff can be aligned to produce mutually beneficial results [8]. This explains why many students have got their industry partners without difficulty. The students' contribution is valuable to the industry partners. As a matter of fact, providing their final report is the condition of their industry partners for most of the students.

The similar practice should be applicable to other subjects which are closely related to industry at Master level. The teaching practice should be adaptable to the third year undergraduate courses as well by making necessary modifications to the required tasks and evaluation criteria to accommodate the analyzing, critique and collaboration abilities of undergraduate students.

\section{SUMMARY}

The findings of this study showed that this inquiry based learning approach is effective; the students valued it more important than classroom lectures and their own literature research.

In this inquiry based learning process, the learning is mutual between the students and their industry partners. The students not only learn from the industry, their contributions are valuable to the industry as well. The industry partners welcome the students' reports and think they are valuable to their business.

A number of ways were used in the communications and email was the most popular one. More online tools could be used to facilitate remote communications.

While the teaching practice is improving, the students' abilities of planning, investigating, analyzing, communicating and reflecting are improving as well.
The teaching practice is validated with WebQuest. Adding a Review and Reflection step should improve the practice.

To deal with the difficulty in finding an industry partner, we encourage the students try more options including those oversea websites. The students should also be encouraged to use their social network. Another possible solution is for the lecturer to maintain a potential industry partner pool.

The similar practice should be applicable to other subjects which are closely related to industry at Master level. By making necessary modifications, it should be adaptable to the third year undergraduate courses as well.

\section{REFERENCES}

[1] M. B. Yoder, "Inquiry Based Learning Using the Internet: Research, Resources", WebQuest. Proceedings of 19th Annual Conference on Distance Teaching and Learning, 2005.

[2] J. Bruner, Culture of education. Cambridge, MA: Harvard University Press, 1996.

[3] B. Woolf, Building Intelligent Interactive Tutors Student-centered strategies for revolutionizing e-learning. 2009 Elsevier Inc. ISBN: 9780-12-373594-2.

[4] S. A. Zainuddin, A. Abdullah and A. G. Downe, "Social Networking Sites For Learning: A Review From Vygotskian Perspective," Proc .of CSIT vol.5 (2011), pp. 41-46, (C) (2011) IACSIT Press, Singapore.

[5] N. Gordon, M. Brayshaw, "Inquiry based Learning in Computer Science teaching in Higher Education", ITALICS Volume 7 Issue 1, pages 2233, June 2008.

[6] J. Allan and M. Street, "The quest for deeper learning: an investigation into the impact of a knowledge-pooling WebQuest in primary initial teacher training", British Journal Of Educational Technology, 38(6), 1102-1112. doi:10.1111/j.1467-8535.2007.00697.x, 2007.

[7] H. Wang, "Collaborative Learning in Internet-Based Distance Education", WorldComp 2011 Proceedings. http://worldcomp.org/p2011/EEE3366.pdf Accessed April 4, 2013.

[8] M. Perkmann and K. Walsh, "University-industry relationships and open innovation: Towards a research agenda", International Journal of Management Reviews, Volume 9, Issue 4, pages 259-280, December 2007. 